\title{
Application of Different Organic Acids on Phosphorus Solubility from Rock Phosphate
}

\author{
Aftab Jamal*, Azam Khan, Muhammad Sharif and Hifsa Jamal \\ ${ }^{1}$ Department of Soil \& Environmental Sciences, Khyber Pakhtunkhwa Agricultural University, \\ Peshawar, Pakistan \\ ${ }^{2}$ Department of Chemistry, Abdul Wali Khan University, Mardan, Pakistan \\ aftabses98@gmail.com
}

\section{Keywords: Rock Phosphate, Oxalic acid, Humic acid}

\begin{abstract}
An incubation experiment was conducted on P solubilization from rock phosphate (RP) through different organic acids such as oxalic acid, citric acid, acetic acid, humic acid and sulphur in the laboratory of the Department of Soil and Environmental Sciences, KP Agricultural University Peshawar during fall 2011. The experiment was laid in a complete randomize design. There were three replications with six treatments. The organic acids were used at the rate of $2 \%$ for $50 \mathrm{~g}$ RP in $250 \mathrm{ml}$ conical flasks. These samples were kept in an incubator at $25^{\circ} \mathrm{c}$ for four months and analysed for Mehlic-3 extractable $\mathrm{P}$ and $\mathrm{pH}$ values after 20 days interval. Statistical analyses were made and maximum $P$ concentration of $1.52 \%$ was observed in the treatment of oxalic acid mixed with RP followed by the treatments of RP mixed with humic acid with P concentration of $0.368 \%$. Rapid increases in P solubility from RP by mixing with oxalic acids were noted up to $60^{\text {th }}$ days of incubation period and then remained stable after this period. Solubilization of $\mathrm{P}$ from RP by mixing with other organic acids was inconsistent. The $\mathrm{pH}$ in treatment of citric acid mixed with $\mathrm{RP}$ was noted as 5.64, followed by the treatments of oxalic acid with $\mathrm{pH}$ values of 6.31 . A dramatic increase in $\mathrm{pH}$ value of 9.33 was observed in the treatment of RP mixed with humic acid. It is because the humic acid contains sodium salt and sodium hummate causes increase in its $\mathrm{pH}$ values.
\end{abstract}

\section{Introduction}

Phosphorus plays a dominant role in plant nutrition and development. Even though $\mathrm{P}$ is widely distributed in nature, yet in most of the soils $\mathrm{P}$ availability to the in soluble form is very limited, only $0.1 \%$ is available to plants [1]. In the form of phosphate fertilizers, phosphorous are added to the soil part of which is utilized by plants and almost more than $70 \%$ are converted into complexes such as iron phosphate, calcium phosphate and aluminium phosphate [2,3]. Due to the high cost of phosphatic fertilizers there is a need for alternative sources. The practical use of rock phosphate (RP), in recent years attributes much attention of researcher in this regards to obtain more valuable products. At $\mathrm{pH}$ higher than 6 rock phosphate availability is restricted to the plants and bears lower yield as compared with the soluble phosphate $[4,5]$. That is why the farmers hesitate to utilize RP directly.

Many traditional techniques are used such as thermal alteration or partial acidulation require substantial capital investments in order to increase the solubility of P from RP, however alternative approaches are also required to increase the availability of $\mathrm{P}$ from RP [5]. One approach for RP solubilization is the application of microorganisms able to excrete organic acids like oxalic acids, citric acids, acetic acids etc. It has been repeatedly shown that low molecular weight organic acids can strongly increase phosphorous solution concentration by mechanisms by creating favourable environment for $\mathrm{P}$ solubilization involving chelation and exchange reaction $[7,8]$. Filamentous fungi are widely used as producers of organic acids $[9,10]$ and particularly mycorrhiza, [11], some Aspergillus and pencillium species have been tested by inoculating directly into the soil in order to solubilize RP [12, 13]. Inoculation of phosphate solubilizing mycorrhizal fungi improves the physico-chemical, biochemical and biological properties of RP amended soil [14]. 
In arid and semi-arid regions, the application of RP is not common because of alkaline nature, high $\mathrm{pH}$, low organic matter as well as less solubility of $\mathrm{P}$ in these soils. Numerous investigations on soil $\mathrm{pH}$, particle size of $\mathrm{RP}$, and concentrations of $\mathrm{Ca}$ and $\mathrm{P}$ in soil solution have examined the solution of RP in soils and its subsequent effect on soil availability [15]. However, the availability of plant nutrients is limited in calcareous soils because of high base content coupled with high $\mathrm{pH}$ as well as the presence of carbonate minerals [16]. In calcareous soils $\mathrm{P}$ fertilizers shows less efficiency because of the reaction with $\mathrm{Ca}$ forming minerals such as di calcium phosphate dehydrate octa calcium phosphate and eventually hydroxyl-apatite [17]. Hence, sulphuric acid or phosphoric acid with RP is used to process chemically with the aim to convert into soluble phosphate fertilizers. Most soil microorganisms such as bacteria, fungi and actinomycetales have the capability to change insoluble phosphates to soluble forms.

Keeping in view the significance of organic acids to create favourable environment for $\mathrm{P}$ solubilization from RP, this incubation study was initiated to determine the degree extent of P solubilization from RP through mixing with different organic acids.

\section{Materials and Methods}

An incubation experiment was conducted on $\mathrm{P}$ solubilization from rock phosphate (RP) through different organic acids such as oxalic acid, citric acid, acetic acid, humic acid and sulphur in the laboratory of the Department of Soil and Environmental Sciences, KP Agricultural University Peshawar during 2011. The experiment was laid in a complete randomize design. There were three replications with six treatments. The organic acids were used at the rate $2 \%$ for $50 \mathrm{~g} \mathrm{RP}$ in $250 \mathrm{ml}$ conical flasks. These samples were kept in an incubator at $25^{\circ} \mathrm{c}$ for four months and analysed for Mehlic-3 extractable $\mathrm{P}$ and $\mathrm{pH}$ values after 20 days interval.

The treatment combinations were as follows:

1. Rock phosphate (RP)

2. RP+ Oxalic acid

3. RP+ Citric acid

4. $\mathrm{RP}+$ Acetic acid

5. RP+ Humic acid

6. $\mathrm{RP}+$ Sulfur

\section{Collection of Rock phosphate samples}

Ground RP from Hazara region was brought into the laboratory of the Department of Soil and Environmental Sciences for this experiment.

\section{Mehlic-3 Extractable P}

Six g materials were taken into a $250 \mathrm{ml}$ conical flask. Fifty ml Mehlic-3 extraction reagent was prepared by dissolving $138.9 \mathrm{~g}$ ammonium fluoride and $73.5 \mathrm{~g}$ EDTA in $1 \mathrm{~L}$ pure water. The $\mathrm{pH}$ was adjusted as $2.0 \pm 0.1$. The material was vigorously shaken for $5 \mathrm{~min}$, filtered through whatman 42 filter paper. The $\mathrm{P}$ concentration of the filterate was then assayed by using spectrophotometer.

\section{pH values}

Ten g materials and $50 \mathrm{ml}$ distilled water was taken in a conical flask and materials water suspension (1:5) was made. The suspension was shaken for 30 minutes on mechanical shaker. The $\mathrm{pH}$ meter and room temperature were adjusted well. $\mathrm{pH}$ was noted by 105 -ion analyser $\mathrm{pH}$ meter [18].

\section{Results and Discussion}

An incubation experiment was conducted to determine $\mathrm{P}$ solubilization from RP through different organic acids such as oxalic acid, citric acid, acetic acid, humic acid and sulphur in the 
laboratory of the Department of Soil and Environmental Sciences, KP Agricultural University Peshawar during 2011. There were three replications with six treatments. The organic acids were used at the rate $2 \%$ for $50 \mathrm{~g}$ RP in $250 \mathrm{ml}$ conical flasks. These samples were kept in an incubator at $25^{\circ} \mathrm{c}$ for 120 days and were analysed for Mehlic-3 extractable $\mathrm{P}$ and $\mathrm{pH}$ after every 20 days interval. The data recorded during this investigation are presented in Table 1.

Table 1. Effect of organic acids on P solubility from RP with time.

\begin{tabular}{|l|c|c|c|c|c|c|}
\hline \multirow{2}{*}{ Treatment } & \multicolumn{7}{|c|}{ Dates of data recording } \\
\cline { 2 - 7 } & $01 / 07 / 11$ & $21 / 07 / 11$ & $11 / 08 / 11$ & $31 / 08 / 11$ & $20 / 9 / 2011$ & $10 / 10 / 11$ \\
\hline Rock phosphate (RP) & 0.124 & 0.412 & 0.108 & 0.039 & 0.052 & 0.025 \\
\hline RP+ Oxalic acid & 0.642 & 0.96 & 1.40 & 1.48 & 1.50 & 1.52 \\
\hline RP+ Citric acid & 0.195 & 0.159 & 0.18 & 0.13 & 0.50 & 0.136 \\
\hline RP+ Acetic acid & 0.134 & 0.59 & 0.137 & 0.046 & 0.127 & 0.053 \\
\hline RP+ Humic acid & 0.105 & 0.114 & 0.118 & 0.035 & 0.087 & 0.368 \\
\hline RP+ Sulfur & 0.56 & 0.12 & 0.28 & 0.04 & 0.24 & 0.226 \\
\hline
\end{tabular}

Table 1 illustrates the results of an experiment on P solubilization from RP through mixing with different organic acids such as oxalic, citric, acetic humic acid and sulphur. Statistical analyses were made for data regarding P solubility from RP indicate that maximum P concentration of 1.52\% was observed in the treatment of oxalic acid mixed with RP followed by the treatments of RP mixed with humic acid with $\mathrm{P}$ concentration of $0.368 \%$ (Fig. 1). Comparatively more P was solubilized from RP through mixing with oxalic acids. Rapid increases in P solubility from RP by mixing with oxalic acids were noted up to $60^{\text {th }}$ days of incubation period and then remained stable after this period. Solubilization of P from RP by mixing with other organic acids was inconsistent (Fig. 1).

Data regarding $\mathrm{pH}$ values are presented in Table 2 and Fig. 2. Data show a $\mathrm{pH}$ of 7.4 in the treatment having only RP after 120 days of incubation period but in other treatments where RP is mixed with organic acids such as oxalic, citric, acetic, humic acid and sulfur, $\mathrm{pH}$ values showed a steady decrease with a narrow range of fluctuation.

Table 2. Effect of organic acids on $\mathrm{pH}$ values.

\begin{tabular}{|l|c|c|c|c|c|c|}
\hline \multirow{2}{*}{ Treatment } & \multicolumn{7}{|c|}{ Dates of data recording } \\
\cline { 2 - 7 } & $01 / 07 / 11$ & $21 / 07 / 11$ & $11 / 08 / 11$ & $31 / 08 / 11$ & $20 / 9 / 2011$ & $10 / 10 / 11$ \\
\hline $\begin{array}{l}\text { Rock phosphate } \\
\text { (RP) }\end{array}$ & 8.29 & 8.11 & 8.44 & 7.89 & 7.74 & 7.4 \\
\hline RP+ Oxalic acid & 5.82 & 6.01 & 6.11 & 6.25 & 6.22 & 6.31 \\
\hline RP+ Citric acid & 6.01 & 6.28 & 5.84 & 6.22 & 5.7 & 5.64 \\
\hline RP+ Acetic acid & 6.58 & 6.94 & 6.95 & 7.07 & 6.89 & 6.77 \\
\hline RP+ Humic acid & 10.31 & 9.9 & 9.76 & 9.55 & 9.41 & 9.33 \\
\hline RP+ Sulfur & 7.82 & 8.24 & 8.30 & 7.91 & 7.66 & 7.23 \\
\hline
\end{tabular}

The $\mathrm{pH}$ in treatment of citric acid mixed with RP was noted as 5.64, followed by the treatments of oxalic acid with $\mathrm{pH}$ values of 6.31. A dramatic increase in $\mathrm{pH}$ value of 9.33 was observed in the treatment of RP mixed with humic acid. It is because the humic acid contains sodium salt and sodium hummate causes increase in its $\mathrm{pH}$ values. These results are in consistency with [19] who observed the similar results. 


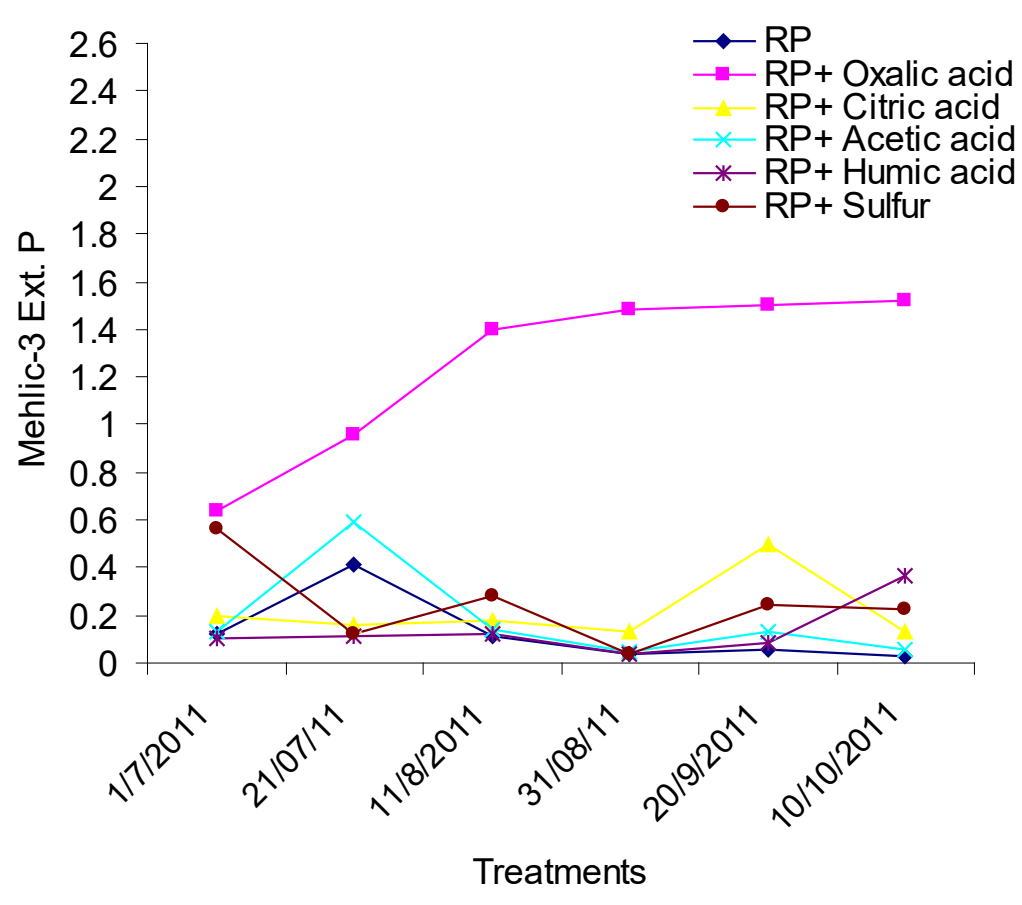

Figure 1. Effect of organic acids on P solubility from RP with time.

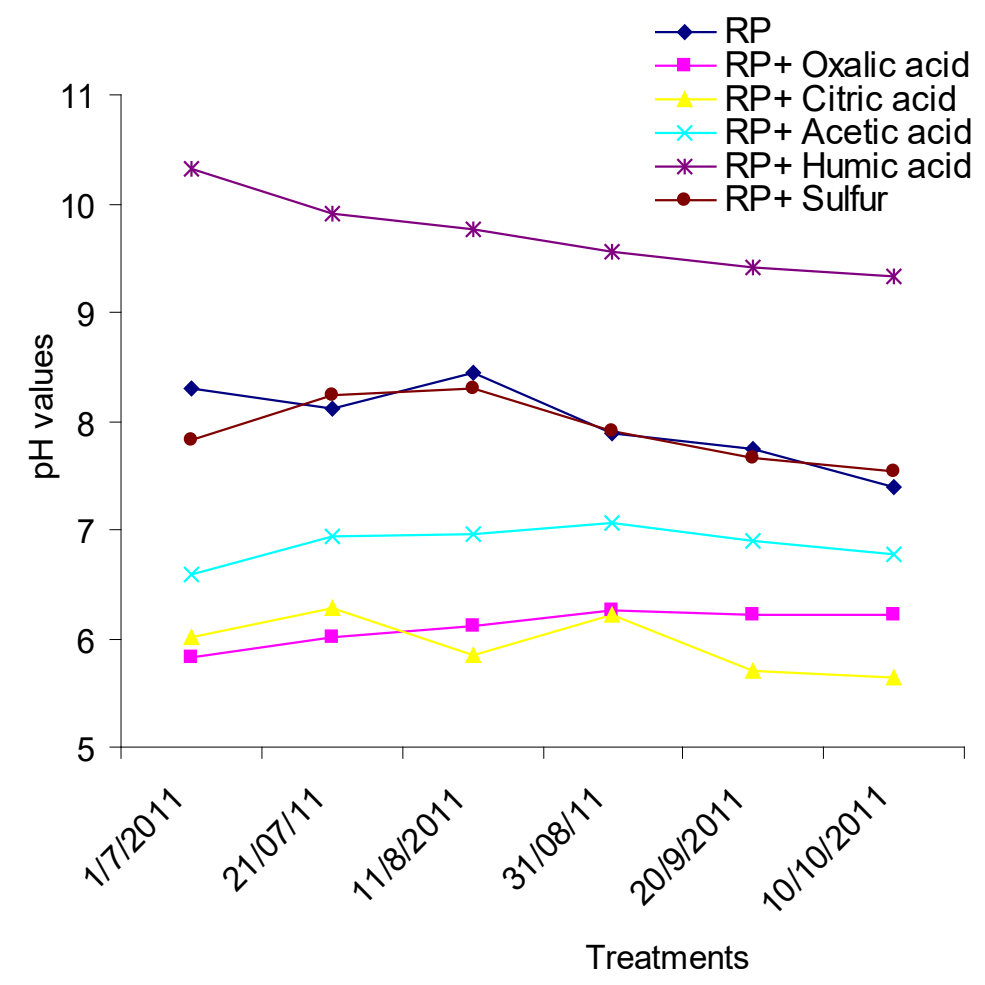

Figure 2. Effect of organic acids mixed with RP on $\mathrm{pH}$ values.

As most of the traditional techniques to increase the solubility of P from RP such as thermal alteration or partial acidulation require substantial capital investments, there is a need for alternative approaches to increase the availability of P from RP [6]. One approach for RP solubilization is the application of microorganisms able to excrete organic acids like oxalic acids, citric acids, acetic acids etc. It has been repeatedly shown that low molecular weight organic acids can strongly increase phosphorous solution concentration by mechanisms by creating favourable environment for $\mathrm{P}$ solubilization involving chelation and exchange reaction [7, 8]. Filamentous fungi are widely used as producers of organic acids [9, 10], and particularly mycorrhiza, [11], some Aspergillus and 
pencillium species have been tested by inoculating directly into the soil in order to solubilize RP $[12,13]$. Inoculation of phosphate solubilizing mycorrhizal fungi improves the physico-chemical, biochemical and biological properties of RP amended soil [14]. It has also been reported that the available $\mathrm{P}$ and aggregate stability levels, higher soil $\mathrm{C}$ levels, enzyme activities and lower soil $\mathrm{PH}$ were reported due to inoculation of these fungi.

\section{Conclusions}

Comparatively more $\mathrm{P}$ was solubilized from RP through mixing with oxalic acids. Rapid increases in P solubility from RP by mixing with oxalic acids were note up to $60^{\text {th }}$ days of incubation period and then remained stable after this period. Solubilization of $\mathrm{P}$ from RP by mixing with other organic acids was inconsistent. Further research is suggested to solubilize P from RP mix with different organic acids to determine the extent and degree of their P solubility enhancement and their effects on growth of various crops in different agro-ecological zones of Pakistan.

\section{Conflict of Interest}

The authors declare that there is no conflict of interest.

\section{References}

[1] C.Q. Xiao et al., Biosolubilization of rock phosphate by three stress-tolerant fungal strains, Appl. Biochem. Biotechnol. 165 (2011) 719-727.

[2] V. Mittal et al., Stimulatory effect of phosphate solubilizing fungal strains (Aspergillus awamori and Penicillium citrinum) on the yield of chickpea (Cicer arietinum L. cv. GPF2), Soil Biol. Biochem. 40 (2008) 718-727.

[3] V. Narsian, H.H. Patel, Aspergillus aculeatus as rock phosphate solubilizer, Soil Biol. Biochem. 32(4) (2000) 559-565.

[4] W.I.A. Saber, K.M. Ghanem, M.S. El-Hersh, Rock phosphate solubilization by two isolates of Aspergillus niger and Penicillium sp. and their promotion to mung bean plants, Research Journal of Microbiology. 4(7) (2009) 235-250.

[5] F.E. Khasawneh, E.C. Doll, The use of phosphate rock for direct application to soils, Adv. Agron. 30 (1979) 159-206.

[6] B. Vanlauwe et al., Utilization of rock phosphate by crops on a representative topsequence in the Northern Guinea savanna zone of Nigeria: response by Mucuna pruriens, Lablab purpureus and maize, Soil Biol. Biochem. 32(14) (2000) 2063-2077.

[7] M.S. Khan et al., Plant growth promotion by phosphate solubilizing fungi-current perspective, Arch. Agron. Soil Sci. 56(1) (2010) 73-98.

[8] Z.L. He, W. Bian, J Zhu, Screening and identification of microorganisms capable of utilizing phosphate adsorbed by goethite, Comm. Soil Sci. Plant Anal. 33(5-6) (2002) 647-663.

[9] M. Fenice et al., Application of encapsulated Penicillium variabile P16 in solubilization of rock phosphate, Bioresour. Technol. 73(2) (2000) 157-162.

[10] M.R. Khan, S.M. Khan, Effect of root-dip treatment with certain phosphate solubilizing microorganisms, Bioresour. Technol. 85(2) (2002) 213-215.

[11] M.S. Khan, A. Zaidi, P. Wani, Role of phosphate solubilizing microorganisms in sustainable agriculture - A review, Agron. Sustain. Develop. 27 (2007) 29-43. 
[12] S.A. Wakelin et al., Phosphate solubilization by Penicillium sp. closely associated with wheat roots, Biol. Fertil. Soils. 40(1) (2004) 36-43.

[13] P.A. Wani, M.S. Khan, A. Zaidi, Synergistic effects of the inoculation with nitrogen fixing and phosphate solubilizing rhizobacteria on the performance of field grown chickpea, J. Plant Nutr. Soil Sci. 170(2) (2007) 283-287.

[14] F. Caravaca et al., Comparing the effectiveness of mycorrhizal inoculation and amendment with sugar beet, rock phosphate and Aspergillus niger to enhance field performance of the leguminous shrub Dorycnium pentaphyllum L., Appl. Soil Ecol. 25(2) (2004) 169-180.

[15] Z.L. He et al., Dissolution characteristic of central Florida phosphate rock in an acidic sandy soil, Plant Soil. 273(1-2) (2005) 157-166.

[16] H. Marschner, Mineral nutrition of higher plants, 2nd ed., Academic press, London, 1995.

[17] A.B. Leytem, R.L. Mikkelsen, The nature of phosphorus in calcareous soils, Better Crops. 89(2) (2005) 11-13.

[18] E.O. Mc Lean, Soil pH and lime requirement, in: A.L. Page, R.H. Miller, D.R. Keeny (Eds.), Methods of Soil Analysis, Part 2. Chemival and Microbiological Properties, no. 9, $2^{\text {nd }}$ ed., 1982, pp. 199-208.

[19] R. Ivanova, D. Bojinova, K. Nedialkova, Rock phosphate solubilization by soil bacteria, Journal of the University of Chemical Technology and Metallurgy. 41(3) (2006) 297-302. 